\title{
Conflitos e Agressões entre Bebês e Diferentes Atributos de Brinquedos: Um Estudo Experimental
}

\author{
Lucas Tadeu Garcia*, Nancy Vinagre Fonseca de Almeida \& Maria Stella Coutinho de Alcântara Gil \\ Universidade Federal de São Carlos, São Carlos, Brasil
}

\begin{abstract}
RESUMO
Este estudo investigou a relação entre a ocorrência de conflitos e agressões nas interações entre bebês e o tipo e tamanho dos brinquedos disponíveis. Doze bebês, de dois a três anos, foram filmados em situação de brincadeira livre em quatro condições experimentais diferentes. As interações foram descritas empregando-se um sistema de classificação que definiu interações amistosas ou agonísticas e seus subtipos, e foram registrados episódios de agressão. A disputa pelos objetos foi o conflito preponderante em todas as condições, e houve correlação significativa entre o tipo de brinquedo e a frequência de agressões, com o predomínio de episódios na condição de "sucata grande". Os resultados demonstraram que certas propriedades dos brinquedos podem afetar a qualidade das interações entre os bebês.
\end{abstract}

Palavras-chave: bebês; interação entre pares; conflito; agressão; brinquedos.

\section{ABSTRACT \\ Conflicts and Aggression Among Infants and Different Attributes of Toys: An Experimental Study}

This study investigated the relationship between the occurrence of conflicts and aggressions in infant peer interactions and the type and size of toys available. Twelve children, 2 to 3 -years-old, were videotaped in a free play situation in four different experimental conditions. The interactions were described by means of a categorization system which defined interactions as friendly or agonistic and its subtypes, and the episodes of aggression were recorded. There was significant correlation between the type of toy available and the frequency of aggression, with a higher prevalence of episodes in the "big scrap" condition. Struggle for object was the predominant conflict in all conditions. The results demonstrated that certain toys' properties can influence the interactions between children.

Keywords: babies; peer interaction; conflict; aggression; toys.

Conflitos e comportamentos agressivos em crianças pequenas têm sido estudados de diferentes pontos de vista, no que diz respeito aos padrões de ocorrência ao longo do desenvolvimento. Para Hay, Payne e Chadwick (2004), o estudo das interações entre coetâneos pode ter um importante valor para o planejamento de intervenções educacionais, especialmente pelo fato de que a ocorrência de agressão nas relações entre crianças pequenas permitiria prever a manifestação de comportamentos agressivos mais tarde na vida do indivíduo. Alguns autores têm destacado que aos dois anos de idade há um pico de ocorrência de episódios de agressão, que diminuem à medida que o bebê adquire linguagem (Hay et al., 2004; Shaw, 2006). Uma das características das interações de crianças nesta idade é que, por volta dos dois anos, elas são especialmente voltadas para os objetos e os conflitos e agressões são, na maior parte das vezes, de natureza instrumental, ou seja, ligadas à negociação da posse desses objetos (Hay, et al., 2004). Este fato torna importante o estudo da relação entre a qualidade das interações e o uso de objetos mediadores, e alguns estudos têm sido conduzidos nesse sentido (Sager \& Sperb, 1998).

\footnotetext{
Endereço para correspondência: Lucas Tadeu Garcia - garcialt@ hotmail.com
} 
No entanto, para aprofundar a investigação da relação entre as interações conflituosas ou agonísticas, de crianças pequenas e os objetos mediadores das interações, é importante caracterizar de forma mais ampla os estudos sobre a relação entre estes objetos e outros aspectos das interações entre pares. Vandell, Wilson e Buchaman (1980), por exemplo, verificaram um efeito significativo da presença do brinquedo sobre a forma e a quantidade de interações infantis, identificando maior número de conflitos na ausência do brinquedo. Jacobson (1981), por sua vez, observou que a despeito de um menor número de interações ocorrerem na presença de objetos elas tendem a ser mais duradouras.

Diferentes tipos de brinquedo também influenciam as características das interações entre as crianças. Rubin e Howe (1985) constataram que alguns materiais mais do que outros propiciavam determinadas brincadeiras. Eles verificaram que brincadeiras com argila, areia e água são mais solitárias, enquanto que as brincadeiras com bonecas, carrinhos e jogos de chá são propícias à imaginação e ao faz-de-conta. Mello e Sperb (1997) realizaram uma revisão da literatura acerca dos materiais utilizados em situação de brincadeira e constataram que a estrutura dos objetos pode ser classificada em diversos termos como mais ou menos estruturada, mais ou menos específica e mais ou menos realística. De forma geral, os estudos analisados pelas autoras mostraram que o número de interações entre as crianças era maior quando a brincadeira era realizada com objetos de baixa especificidade, ou sucatas, como cilindros de papelão e blocos de madeira, do que com objetos de alta especificidade, ou industrializados, como bonecas e carrinhos.

Mais especificamente em relação aos conflitos, Sager e Sperb (1998) investigaram sua ocorrência na interação de pares de crianças, com idade entre três e quatro anos, e variáveis como: o tipo de atividade (exercício, simbólica, de acoplagem e de regras); o tipo de brinquedo (acadêmicos, orientados para adulto e para criança, naturais e nenhum objeto) e o gênero das crianças. Identificaram maior ocorrência de conflitos quando os objetos utilizados eram brinquedos orientados para criança (carrinhos, bonecos etc.), especialmente para grupos de meninos. Brinquedos orientados para adulto (sucata) foram relacionados à maior ocorrência de conflitos em grupos mistos. Os dados encontrados pelos autores também indicam um predomínio de conflitos em atividades do tipo simbólicas, quando comparado aos outros tipos de ativida- des em sala. Para os autores, atividades que envolvem negociação de significado são facilitadoras do surgimento de conflitos.

O tamanho dos brinquedos também foi identificado como uma variável importante sobre o tipo de interação. De Stefano e Mueller (1982), ao observarem as interações de bebês de 18 meses, identificaram que quando os brinquedos disponíveis eram grandes (não portáteis), as crianças tendiam a interagir mais do que nas situações nas quais os brinquedos eram pequenos. Da mesma forma, os brinquedos grandes favoreceram a maior ocorrência de afetos positivos, quando comparado à condição na qual os brinquedos disponíveis eram pequenos.

O número de brinquedos disponível para pequenos grupos de crianças foi outra variável estudada em relação às brincadeiras que desencadeavam. Caplan, Vespo, Pedehsen e Hay (1991) avaliaram a natureza dos conflitos que surgiam nas brincadeiras em tríades de crianças entre um e dois anos, ou seja, se eram de natureza instrumental ou social. Os bebês foram observados em condições em que havia ou não duplicatas dos materiais disponíveis. Os autores verificaram que houve um grande número de conflitos do tipo disputa, mesmo na condição de duplicata. Segundo os autores, estes conflitos embora aparentemente relacionados ao material, tinham um evidente caráter social, como pode ser notado pelo fato de que crianças, em diversas ocasiões, tendo obtido o objeto do outro, o largavam, deixavam-no de lado ou retinham-no sem brincar.

Com relação a episódios de agressão, um estudo recente avaliou interações em crianças entre 18 e 30 meses em dois contextos diferentes; um no qual os brinquedos eram apresentados de forma sugestiva, ou seja, como parte de um cenário, estabelecendo o tipo de brincadeira a ser realizada, e outro onde os brinquedos eram apresentados de forma não estruturada (Shoeth \& Klein, 2010). Os autores observaram que os contextos afetaram diferentemente as interações entre os pares. As crianças mais novas demonstraram um menor número de agressões quando o contexto era estruturado, enquanto as crianças mais velhas agrediram menos na outra condição.

Os estudos citados anteriormente demonstraram que a ocorrência de conflitos e agressões nas interações entre pares de crianças pode ser diferente diante de certos aspectos usuais no ambiente educacional da 
creche, tais como a disponibilidade de brinquedos, o tipo e o tamanho dos brinquedos, bem como a estrutura da brincadeira. Neste estudo, optou-se por investigar as variáveis "tipo" e "tamanho" de brinquedo, uma vez que dentre os estudos analisados, nenhum os investigou concomitantemente. Além disso, as categorias de interação denominadas conflito e agressão raramente têm sido tratadas separadamente (Lober \& Hay, 1997; Sager \& Sperb, 1998) e, considerando que "conflito" é uma categoria que abrange um amplo espectro de interações, que podem servir como contexto para o ensino de estratégias para resolução destes mesmos conflitos (Jones, 2004), considerou-se importante analisá-las separadamente.

Considerando ainda, que o tema das interações entre pares continua carente de estudos (Anjos, Amorim, Vasconcelos \& Rosseti-Ferreira, 2004), este trabalho teve como objetivo investigar a relação entre a ocorrência de conflitos e de agressões nas interações entre coetâneos, com idade entre dois e três anos, e o tipo e tamanho de brinquedos disponíveis, bem como analisar a natureza do conflito. Foram utilizadas categorias de análise derivadas da observação e da categorização dos registros realizados durante as brincadeiras de crianças em uma creche, de forma a possibilitar uma análise mais detalhada das categorias de conflitos identificadas.

\section{MÉTODO}

\section{Participantes}

Doze bebês, cinco meninos e sete meninas, com idades entre 24 e 36 meses, frequentadores de uma creche filantrópica da cidade de São Carlos, no interior do Estado de São Paulo. Todos os participantes provinham de famílias socioeconomicamente desfavorecidas, moradoras de um bairro periférico da cidade.

\section{Local}

As sessões foram realizadas em uma das salas e no parque da creche onde as crianças brincavam com a presença da educadora. Havia três acessos à sala por portões de madeira que tinham ligação com duas outras salas e a uma área externa. A sala era mobiliada com uma mesa de madeira encostada em uma das paredes onde as crianças eventualmente subiam ou brincavam com os objetos. Junto à mesa havia um banco longo de madeira no qual a educadora sentava- -se, e que as crianças utilizavam como assento ou suporte nas suas brincadeiras.

\section{Material}

Foram utilizados quatro tipos de brinquedo: 1) manufaturados grandes: carros de vários tipos, bonecas de plástico e de pano, bolas, bichos de pelúcia; 2) manufaturados pequenos: carrinhos, bonequinhas, bolas pequenas, bonecos de pelúcia pequenos; 3) $\mathrm{Su}$ cata grande: garrafas PET de dois litros, caixas de papelão, latas de óleo cinco litros, potes de maionese cinco litros e baldes; e 4) Sucata pequena: garrafas PET de $500 \mathrm{ml}$, rolinhos de papelão, latas de molho de tomate, potes de xampu. Grande e pequeno foram definidos, respectivamente, pela dificuldade ou possibilidade de deslocamento do objeto pelas crianças.

Para fins de registro, foram utilizadas duas câmeras VHS dispostas em posições opostas no ambiente de forma a captar o maior número possível de interações entre as crianças.

\section{PROCEDIMENTO}

Os pesquisadores, crianças e educadoras estavam familiarizados uns com os outros, ainda assim, foram realizadas duas sessões, de 50 minutos cada uma, para habituação das crianças às condições experimentais.

As crianças foram convidadas a participar de situações semiestruturadas nas quais poderiam brincar livremente com os objetos disponíveis e que caracterizavam as situações experimentais. Após as duas sessões de habituação, os bebês foram submetidos a oito sessões nas diferentes condições, programadas e identificadas pelos tipos de brinquedo disponível. Cada condição recebeu uma identificação e um código de acordo com cada condição $(\mathrm{C})$ oferecida às crianças: $\mathrm{C} 1$ manufaturado grande; $\mathrm{C} 2$ manufaturado pequeno; C3 sucata grande; $\mathrm{C} 4$ sucata pequena. Cada sessão foi realizada duas vezes, na sequência $\mathrm{C} 1, \mathrm{C} 2, \mathrm{C} 3$ e C4, cada uma delas com 50 minutos de duração. O número de crianças em cada sessão variou de nove a 12 .

Cada condição era estruturada antes do início das sessões com a colocação dos brinquedos na sala. Após a preparação da sala, as crianças entravam no ambiente junto com a educadora e podiam brincar livremente com os objetos à disposição. As duas câmeras VHS eram acionadas simultaneamente no momento em que o último participante entrava no ambiente e então as portinholas de madeira que permitiam acesso à sala 
eram fechadas. Nesse momento era iniciada a contagem de tempo da sessão. As crianças eram livres para deixar a sala para serem atendidas em necessidades específicas ou quando não se adaptassem à situação.

Dois experimentadores operaram as câmeras focalizando, sobretudo, os lugares onde os bebês permaneciam. Em situações em que um grupo de crianças interagia em um espaço que não estava sendo focalizado por nenhuma das câmeras, modificava-se a posição de uma das câmeras de forma a registrar o grupo específico.

\section{TRATAMENTO E ANÁLISE DE DADOS}

Os registros de cada sessão produzidos pelas duas câmeras independentes foram assistidos, simultaneamente, por dois experimentadores. A reprodução das duas fitas era sincronizada e, a cada episódio de interação, o videoteipe era interrompido para o registro manual de todas as informações acerca de cada episódio interativo no protocolo de análise. Neste protocolo cada interação era classificada de acordo com um conjunto de categorias de análise desenvolvidas previamente, entre elas, se a interação foi ou não mediada pelo objeto, se foi amistosa ou agonística, etc.

Para a elaboração desse protocolo, foram definidas previamente as categorias de análise de episódios interativos. A definição de episódio interativo, considerou o critério discutido por Perosa (1993) e utilizado por Vandell et al. (1980), de contiguidade temporal entre um comportamento socialmente dirigido (CSD) de uma criança em relação a um ou mais pares, e uma reação, dirigida socialmente ou não, àquele comportamento por parte de outra criança. Um CSD foi definido como a coordenação entre um olhar para a outra criança e uma ação como acenar, sorrir, tocar ou vocalizar. Um episódio de interação foi considerado encerrado quando as crianças do grupo de interação deixavam de emitir comportamentos direcionados umas às outras.

Um exemplo de episódio interativo pode ser assim descrito: um bebê que tem um brinquedo em seu poder estende a mão com o brinquedo para outro bebê enquanto olha para ele; em seguida, o outro bebê olha para a criança com o brinquedo e pega o brinquedo da mão da criança que o solta, ao mesmo tempo em que olha para a outra. Em seguida, a criança que pegou o brinquedo vira-se e começa a brincar com o objeto, encerrando a interação.
A partir da definição de episódio interativo foram estabelecidas as demais categorias de análise. Foram definidas duas categorias principais: 1) interação amistosa e 2) interação agonística. Para a análise dos tipos de conflitos, foram definidas quatro subcategorias de interações agonísticas mediadas por objeto, chamadas aqui de modos de interação, a saber: disputa por objeto; uso direto do objeto; atrapalhar brincadeira e agonística acidental, cujas definições e respectivos códigos foram descritos. Com a finalidade de identificar a ocorrência de episódios de interação em relação ao número total de episódios interativos, foram criadas duas categorias relativas às interações amistosas. Desse modo, o sistema de categorias abrangeu todos os episódios, mas a análise dos dados focalizou, predominantemente, as interações agonísticas.

Interação amistosa: Interação na qual as crianças que participaram do episódio estão conjuntamente engajadas em uma mesma atividade e apresentam comportamentos amigáveis em relação ao outro, tais como: sorrir, brincar junto, imitar a ação do outro.

Interação amistosa mediada por objeto: Interação amistosa na qual os envolvidos emitem comportamentos direcionados a um ou mais objetos (olhar para o objeto e emitir ação direcionada), ou quando a ação direcionada a um mesmo objeto inicia uma interação. Exemplo: Quando duas crianças brincavam de empurrar um carrinho uma para outra, alternadamente.

Interação agonística: Um episódio interativo no qual, um comportamento de uma criança direcionado a outra é seguido de uma reação de desconforto, descrita como choro, reclamação vocal, fuga, sinal de submissão (abaixar a cabeça, entregar o brinquedo em posse) ou contra-ataque, por parte do outro membro da díade. Exemplo: quando uma criança está sentada perto da educadora e uma outra criança a empurra para sentar naquele mesmo local, enquanto a primeira começa a chorar.

Interação agonística mediada por objeto: Interação na qual os envolvidos emitem comportamentos direcionados a um ou mais objetos (olhar para o objeto e emissão de ação direcionada), ou quando a ação direcionada a um mesmo objeto inicia uma interação e disto resulta algum sinal de desconforto em um dos participantes da interação. Exemplo: quando uma criança pega o brinquedo de outra que em seguida começa a chorar.

Agressão: O comportamento agressivo pode ser definido pelo efeito de dano, físico ou psicológico,

Interação Psicol., Curitiba, v. 17, n. 1, p. 27-36, jan./abr. 2013 
sobre o outro (Loeber \& Hay, 1997). No entanto, embora menos objetivo, preferiu-se considerar como agressão qualquer comportamento dirigido a outra criança com potencial de causar dano ou dor física (beliscar, segurar, puxar, morder, derrubar, pisar, bater, chutar, arranhar). Para fins de análise, as interações agonísticas nas quais não foram observados episódios de agressão foram registradas como sem agressão, em contrapartida àquelas registradas como com agressão, nas quais os episódios foram observados.

As categorias Interação agonística mediada por objeto foram organizadas em cinco subcategorias:

Disputa por objeto: Episódio no qual um participante apropria-se de um objeto que está em posse de outra criança, seguido de uma reação de desconforto de qualquer um dos membros da díade (choro, reclamação vocal, fuga, retirada ou retenção de objeto, reapropriação de objeto).

Utilização direta do objeto: Episódio no qual um bebê causa desconforto a outro bebê por meio da utilização direta de um dos objetos presentes no ambiente, atingindo outra criança, ou realizando um tipo de brincadeira que possa gerar desconforto, tal como colocar uma caixa de papelão sobre outra criança e se apoiar sobre ela. Por exemplo, quando uma criança coloca um balde de plástico na cabeça de outra criança que começa a chorar, tentando tirar o balde da cabeça.

É importante salientar que quando um episódio interativo era iniciado por uma agressão por parte de uma criança utilizando um objeto, tal como arremessar um carrinho em outra criança, a interação era considerada agonística do tipo utilização direta do objeto com agressão. $\mathrm{O}$ critério para classificar o episódio interativo de modo agonístico levava em conta o início da interação, de forma que, caso um bebê agredisse outro em decorrência de uma disputa, o episódio interativo era considerado disputa por objeto com agressão.

Atrapalhar a brincadeira: Episódio no qual um bebê interrompe a brincadeira de um outro que está em posse de um objeto e tem como conseqüência a reação de desconforto deste último. Por exemplo, quando há uma criança brincando dentro de uma caixa de papelão utilizando-a como "casinha" e outra retira a caixa do lugar sem se apropriar dela. É importante ressaltar que se a criança que atrapalhou a brincadeira da outra se apropriar da caixa para utilizá-la como brinquedo, a situação se configura como um episódio de Disputa por objeto.

Agonística acidental: Episódio no qual um bebê ao manejar um objeto produz reação de desconforto em outro bebê. Por exemplo, quando uma criança está andando pela sala balançando uma boneca grande e acerta outra criança, que começa a chorar. A diferença entre esse tipo de interação e o uso direto do objeto é que neste caso a interação não era iniciada por um comportamento socialmente dirigido.

\section{RESULTADOS}

Foi identificado um total de 460 episódios de interação, em 400 minutos de registro, dos quais 427 $(92,8 \%)$ foram interações mediadas por objeto e em apenas $33(7,2 \%)$ episódios interativos não houve qualquer comportamento dirigido a um objeto. A Figura 1 apresenta o número de interações observadas para cada uma das quatro condições experimentais. $\mathrm{O}$ maior número de episódios de interação registrado foi na condição sucata grande (151), seguida da condição de brinquedos manufaturados pequenos, na qual foram observadas 130 interações. Na condição sucata pequena (92) foi observado um número de interações próximo daquele registrado na condição de manufaturado grande (87). 


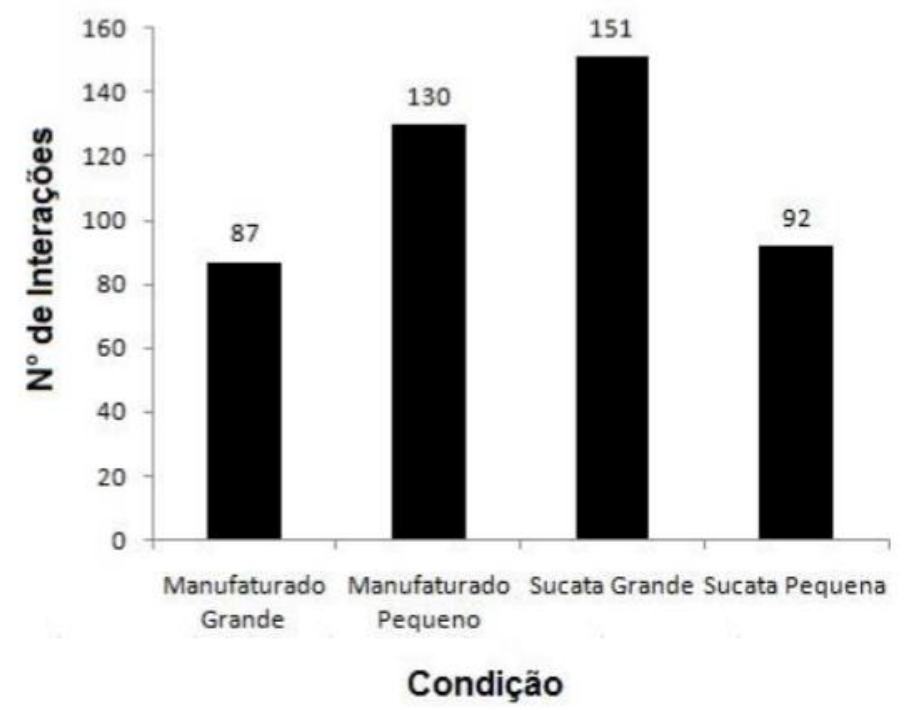

Figura 1. Número total de interações observadas em cada condição experimental.

Com relação à natureza das interações observadas, pode-se notar, pela Tabela 1 , que, dentre o número total de interações, $64,1 \%$ foram do tipo agonística (mediadas e não mediadas pelo objeto) e apenas $35,9 \%$ foram amistosas (mediadas e não mediadas pelo objeto). Analisando a ocorrência dos tipos de interações em cada condição, as maiores frequências relativas de ocorrência de interações do tipo agonísticas incidiram nas categorias manufaturado grande $(75,86 \%)$, sucata grande $(63,58 \%)$ e sucata pequena $(63,04 \%)$. A análise correlacional realizada por meio do software SPSS (versão 15.0) não demonstrou relação significativa entre as variáveis "tipos de interação" e "condição" $\left(\chi^{2}=7,615, \mathrm{df}=3, \mathrm{p}>0,05\right)$.

Tabela 1

Frequências Absolutas e Relativas de Ocorrência dos Diferentes Tipos de Interação em Cada Condição Experimental

\begin{tabular}{lcccc}
\hline \multicolumn{1}{c}{ Condição } & \multicolumn{4}{c}{ Tipo de Interação } \\
& Frequenística & \multicolumn{2}{c}{ Amistosa } \\
& 66 & 75 . Relativa & Frequência & F. Relativa \\
Manufaturado Grande & 75 & 57,69 & 21 & 24,14 \\
Manufaturado Pequeno & 96 & 63,58 & 55 & 42,31 \\
Sucata Grande & 58 & 63,04 & 34 & 36,42 \\
Sucata Pequena & 295 & 64,10 & 165 & 36,96 \\
Total & & & & 35,90 \\
\hline
\end{tabular}

Nota: $\chi^{2}=7,615, d f=3, p>0,05$

Outra variável avaliada foi a agressão física durante as interações agonísticas. A Tabela 2 apresenta as freqüências absolutas e relativas das interações agonísticas com e sem agressão física de acordo com cada condição. As frequiências relativas foram calculadas considerando-se o total de interações com agressão física $(\mathrm{n}=182)$ e sem agressão física $(\mathrm{n}=113)$ para cada uma das condições experimentais. Podemos observar que a maior parte das interações agonísticas $(61,69 \%)$ não foi acompanhada de agressão física. $\mathrm{Na}$ condição de sucata grande observou-se a maior ocorrência de agressão $(50,00 \%)$, seguida da condição manufaturado pequeno $(41,33 \%)$, enquanto a menor frequência foi observada quando os brinquedos utili- 
zados eram do tipo sucata pequena $(24,14 \%)$. No caso dos episódios de agressão, a análise de correlação por meio do cálculo do qui-quadrado indicou uma relação significativa entre o tipo de brinquedo (Condição) e a ocorrência de agressão física durante as interações $\left(\chi^{2}=12,561, \mathrm{df}=3, \mathrm{p}<0,05\right)$.

Tabela 2

Frequências Absoluta e Relativa de Ocorrência de Agressão Física Durante Episódios de Interação Agonística em Cada Condição

\begin{tabular}{lcccc}
\hline \multirow{2}{*}{ Condição } & \multicolumn{4}{c}{ Interações Agonísticas } \\
& Sem Agressão Física & \multicolumn{2}{c}{ Com Agressão Física } \\
& Freqüência & F. Relativa & Freqüência & F. Relativa \\
Manufaturado Grande & 46 & 69,70 & 20 & 30,30 \\
Manufaturado Pequeno & 44 & 58,67 & 31 & 41,33 \\
Sucata Grande & 48 & 50,00 & 48 & 50,00 \\
Sucata Pequena & 44 & 75,86 & 14 & 24,14 \\
Total & 182 & 61,69 & 113 & 38,31 \\
\hline
\end{tabular}

Nota: $\chi^{2}=12,561, d f=3, p<0,05$

No que diz respeito aos modos de interação agonística mediada por objeto, as frequências absolutas e relativas de ocorrência de cada um destes modos, em cada condição, são apresentadas na Tabela 3. As frequiências relativas foram calculadas pela porcentagem de observações de um determinado modo de interação em relação ao número total de interações agonísticas observadas em cada uma das condições experimentais. Podemos observar que houve um predomínio dos conflitos do modo "disputa por objeto" em todas as condições. A maior proporção de "disputas por objeto" ocorreu na condição de manufaturado grande (93,33\%), seguido de manufaturado pequeno $(83,58 \%)$. As condições de sucata apresentaram escores semelhantes no modo "disputa por objeto" com $71,11 \%$ (sucata grande) e $73,21 \%$ (sucata pequena). Podemos notar que entre as condições de sucata foi observada uma grande diferença na proporção de interações agonísticas do modo "utilização direta", sendo que estas constituíram $24,44 \%$ das interações durante a condição de sucata grande e de $8,93 \%$ das interações agonísticas quando o mesmo tipo de brinquedo era de tamanho pequeno. Ainda entre as duas condições de sucata, também podemos notar uma diferença quanto ao modo de interação agonística "atrapalhar brincadeira", tendo a proporção destas interações sido $1,11 \%$ na condição de sucata grande e $12,50 \%$ na condição sucata pequena.

Nas duas condições que envolviam brinquedos manufaturados, podemos observar que a diferença na proporção do modo "disputas por objeto" está relacionada com a maior ocorrência relativa de interações do modo "utilização direta" durante a condição de manufaturado pequeno $(14,93 \%)$ quando comparada à sua ocorrência relativa na condição de manufaturado grande $(5,00 \%)$. A proporção de ocorrência dos outros dois modos de interação agonística, "atrapalhar a brincadeira" e "agonística acidental", foi muito semelhante à proporção nas duas condições de brinquedos manufaturados. No entanto, devido ao fato de terem sido observadas ocorrências iguais a zero para os dois modos de interação e em duas condições, não foi possível submeter os resultados a testes estatísticos e, dessa forma, avaliar se a ocorrência dos modos de interação agonística foi correlacionada significativamente com as condições de brinquedo. 
Tabela 3

Frequências Relativas de Ocorrência dos Modos de Interações Agonísticas em Cada Condição

\begin{tabular}{lcccccccc}
\hline \multirow{2}{*}{ Condição } & \multicolumn{9}{c}{ Modos de Interação Agonística } \\
& \multicolumn{1}{c}{ Ag. Acidental } & Atrapalhar Brincadeira & \multicolumn{2}{c}{ Disputa por Objeto } & \multicolumn{2}{c}{ Utilização Direta } \\
& Freq. & F. Relativa & Freq. & F. Relativa & Freq. & F. Relativa & Freq. & F. Relativa \\
Manufaturado Grande & 0 & 0,00 & 1 & 1,67 & 56 & 93,33 & 3 & 5,00 \\
Manufaturado Pequeno & 1 & 1,49 & 0 & 0,00 & 56 & 83,58 & 10 & 14,93 \\
Sucata Grande & 3 & 3,33 & 1 & 1,11 & 64 & 71,11 & 22 & 24,44 \\
Sucata Pequena & 3 & 5,36 & 7 & 12,50 & 41 & 73,21 & 5 & 8,93 \\
\hline Total & 7 & 2,60 & 9 & 3,30 & 217 & 79,50 & 40 & 14,70 \\
\hline
\end{tabular}

\section{DISCUSSÃO}

Segundo Sager, Sperb, Roazzi e Martins (2003), a literatura tem demonstrado que brinquedos de tamanho grande facilitam a ocorrência de um número maior de interações. Observamos esse efeito quando comparamos o número de interações nas condições sucata grande e sucata pequena. No entanto, ao observarmos as condições de brinquedos do tipo manufaturado, a relação foi inversa. É possível que a definição utilizada para o tamanho dos objetos não esteja de acordo com aquela apresentada na literatura, tal como a de DeStefano e Mueller (1982), segundo a qual os objetos grandes seriam aqueles não portáteis. Neste estudo os objetos grandes eram bem maiores que aqueles utilizados nas condições de objetos pequenos, no entanto, os bebês conseguiam arrastá-los, mesmo que não conseguissem carregá-los, ou seja, poderiam não ser portáteis, mas eram deslocáveis.

Além do efeito sobre o número de interações, esta diferença importante na definição do tamanho dos objetos pode explicar a ausência de relação estatística significativa desta propriedade dos objetos e as proporções de cada tipo de interação. Seria esperado, de acordo com a literatura, que os objetos grandes favorecessem as interações amistosas, enquanto que os objetos pequenos favorecessem as interações agonísticas (DeStefano \& Mueller, 1982). Ainda assim, se os dados relativos ao tamanho dos objetos manufaturados forem comparados, vemos que a condição de manufaturado grande gerou mais interações agonísticas que a condição de manufaturado pequeno. Uma possível explicação pode estar relacionada aos brinquedos utilizados na condição de manufaturado grande. Nesta condição, havia uma quantidade grande de brinquedos disponível para evitar que a quantidade afetasse as interações entre os bebês, porém uma mesma classe de brinquedos (por exemplo, os carrinhos) possuía exemplares de características diferentes e que diferiam quanto a sua atratividade. Assim, houve uma procura maior por aqueles que seriam, em tese, mais atrativos e, consequentemente, geraram um número grande de disputas.

Um resultado importante neste estudo foi o fato de não ter sido identificada diferença significativa no número de interações agonísticas entre as condições de brinquedo manufaturado e as condições de sucata. De acordo com a literatura, os brinquedos do tipo sucata favorecem a negociação de significado nas brincadeiras, enquanto que brinquedos industrializados, como já possuem significados previamente associados, favorecem a negociação do objeto em si e, portanto, favorecem as disputas (Bonica, 1993). Uma possibilidade de explicação aponta o repertório dos participantes do estudo. Por se tratar de bebês de idades bastante variadas, a maior parte deles com repertório verbal pouco desenvolvido, é possível que as trocas de significados durante as brincadeiras, esperadas na condição de sucata, não ocorressem. Isso teria favorecido a negociação direta do brinquedo, aumentando, dessa forma, a probabilidade de conflitos, independentemente da condição.

A freqüência de agressão, no entanto, foi significativamente diferente entre as condições, tendo o menor índice de agressão sido associado às condições sucata pequena e manufaturado grande. A maior frequência de agressões nas interações agonísticas, por sua vez, foi observada na condição de sucata grande. Não foi encontrada evidência na literatura para sustentar estes resultados, no entanto é possível derivar algumas explicações a partir da análise qualitativa das sessões. Por exemplo, apesar da condição de manufaturado ter apresentado a maior freqüência relativa de interações agonísticas, obteve a segunda menor frequência de agressão. Esse resultado talvez possa ser explicado em 
função do tamanho dos objetos que pode ter mantido os bebês afastados, minimizando o contato físico durante as disputas. Na condição de sucata grande, no entanto, os brinquedos permitiam maior aproximação das crianças durante as disputas. Além disso, alguns podiam ser usados como instrumentos de agressão, como no caso das garrafas PET e cilindros de papelão.

Com relação aos modos de interação agonística, observamos um predomínio de disputa por objeto. Esse tipo de conflito tem sido descrito como preponderante em crianças dessa idade e ainda mais novas (Caplan et al., 1991). Segundo Hay e Ross (1982) os conflitos entre bebês nessa idade estão relacionados tanto com o aumento do interesse pelo outro, quanto com o aumento do interesse pelos objetos, o que propicia o surgimento de conflitos. Além disso, há evidência de que crianças dessa idade tendem a ter mais interesse por objetos que estejam na posse de outras crianças, mesmo quando estavam previamente em posse de um objeto identificado como de grande interesse para ela (Bruzek \& Thompson, 2007). Esses resultados podem contribuir para explicar a predominância de conflitos do modo disputa em todas as condições de brinquedo utilizadas.

Outro modo de interação agonística que merece destaque foi o "atrapalhar a brincadeira". Esta categoria foi observada predominantemente na condição de sucata pequena. Nesta condição alguns bebês utilizavam as sucatas para construir pequenas estruturas, o que tornava propício que conflitos iniciassem quando alguns bebês se aproximavam e as desmanchavam, ou mesmo tentavam se apropriar dos objetos que estavam sendo utilizados. No entanto, nem sempre interações iniciadas dessa forma eram agonísticas, uma vez que o jogo de desmanchar pode também se tornar uma brincadeira. De qualquer forma, este é um tipo de conflito que é particularmente facilitado por uma determinada característica da interação dos bebês com o objeto específico.

As maiores frequências relativas de ocorrência do modo de interação agonística "utilização direta do objeto" foram observadas, respectivamente, nas condições de sucata grande e manufaturado pequeno. Com relação aos brinquedos do tipo sucata grande, foram observados muitos incidentes nos quais uma criança colocava um balde sobre a cabeça de outro, ou, ao caminhar com um rolo de papelão acabava atingindo outra criança, iniciando, dessa forma, uma interação conflituosa. A estrutura dos objetos utilizados parece ter favorecido esse modo de interação agonística, no entanto, com relação aos brinquedos manufaturados pequenos, a estrutura dos brinquedos não é tão claramente relacionada com esta forma de iniciar conflitos. Curiosamente, as duas referidas condições de brinquedos foram associadas com uma maior freqüência relativa de agressões.

Nenhum outro modo de interação agonística foi particularmente relacionado com um tipo de brinquedo específico, especialmente devido ao fato de que não foi possível analisar estatisticamente a relação entre essas variáveis. No entanto, é notável que em comparação aos brinquedos manufaturados, os do tipo sucata favoreceram menor ocorrência de disputas e uma maior distribuição dos modos de interações agonísticas entre as outras categorias identificadas. Possivelmente, isso se deva ao fato de que a forma com a qual as crianças brincam com os manufaturados é menos flexível, dado que é determinada pela estrutura dos brinquedos cuja função é previamente estabelecida, fazendo com que os conflitos se concentrem principalmente na obtenção de um brinquedo específico. Como podemos observar, as formas diversificadas de brincar durante a atividade com sucata, também implicam possibilidades de ocorrência de formas diferentes de conflitos, aos quais os educadores precisam também estar atentos.

De maneira geral, os resultados aqui apresentados não foram consistentes com a literatura no que diz respeito à relação entre variáveis de contexto, no caso os diferentes tipos e tamanhos de brinquedo, e as interações entre bebês. Em grande parte dos casos, os resultados podem decorrer da caracterização dos objetos (tipo e tamanho), ou mesmo, do repertório dos participantes. Foi possível, no entanto, descrever categorias de interações conflituosas ainda não apresentadas na literatura. Certamente, as categorias apresentadas estão longe de esgotar as possibilidades de análise, mas permitiram um detalhamento das relações entre os bebês quando estes brincam com diferentes tipos de brinquedos.

\section{REFERÊNCIAS}

Anjos, A. M., Amorim, K. S., Vasconcelos, C. R. F. E., \& Rosseti-Ferreira, M. C. (2004). Interações de bebês em creche. Estudos de Psicologia, 9, 513-522.

Bruzek, J. L., \& Thompson, R. H. (2007). Antecedent effects of observing peer play. Journal of Applied Behavior Analysis, 40, 327-331. 
Bonica, L. (1993). Negotiation among children and pretend play. In M. Stamback \& H. Sinclair (Eds.), Pretend play among 3years-olds (pp. 55-78). Hillsdale, NJ: Erlbaum.

Caplan, M., Vespo, J., Pedehsen, J., \& Hay, D. F. (1991). Conflict and its resolution in small groups of one-and two-year-olds. Child Development, 62, 1513-1524.

De Stefano, C. T., \& Muller, E. (1982) Environmental determinants of peer social activity in 18-month-old-males. Infant Behavior and Development, 5, 175-183.

Hay, D. F., Payne, A., \& Chadwick, A. (2004). Peer relations in childhood. Journal of Child Psychology and Psychiatry, 45, 84-108.

Hay, D. F., \& Ross, H. S. (1982). The social nature of early conflict. Child Development, 53, 105-113.

Jacobson, J. L. (1981). The role of inanimate objects in early peer interaction. Child Development, 52, 618-626.

Jones, T. (2004). Conflict resolution education: The field, the findings, and the future. Conflict Resolution Quarterly, 22, 233-267.

Loeber, R., \& Hay, D. (1997). Key issues in the development of aggression and violence from childhood to early adulthood. Annual Review of Psychology, 48, 371-410.

Mello, C. O., \& Sperb, T. M. (1997). Para além dos objetos, sem perdê-los de vista. Psicologia: Teoria e Pesquisa, 13, 153-160.

Perosa, G. B. (1993). O conceito de interação nos estudos com crianças pequenas. Psicologia: Teoria e Pesquisa, 9, 401-413.

Rubin, K. H., \& Howe, N. (1985). Toys and play behavior: An overview. Topics in Early Childhood Special Education, 5, 1-9.
Sager, F., \& Sperb, T. M. (1998). O brincar e os brinquedos nos conflitos entre crianças. Psicologia: Reflexão e Crítica, 11, 309-326.

Sager, F., Sperb, T. M., Roazzi, A., \& Martins, F. M. (2003). Avaliação da interação de crianças em pátios de escolas infantis: Uma abordagem da psicologia ambiental. Psicologia: Reflexão e Crítica, 16, 203-215.

Shaw, D. S. (2006). The development of aggression in early childhood. In H. E. Fitzgerald, B. M. Lester \& B. M Zuckerman (Eds.), The crisis in youth mental health: Vol. 1. The organization and prevention of children's mental health problems. Westport, CT: Greenwood.

Shoeth, C., \& Klein, P. S. (2010). Effects of variation in toy presentation on social behaviour of infants and toddlers in childcare. Early Child Development and Care, 180, 823-834.

Vandell, D. L, Wilson, K. S., \& Buchaman, N. R. (1980). Peer interaction in the first year of life: An examination of its structure, content, and sensitivity to toys. Child Development, 51, 481-488.

Recebido: 20/10/2010

Última revisão: 10/10/2012

Aceito: $17 / 11 / 2012$ 